\title{
Strategic Intervention Material (SIM)-based Instruction in Teaching Global Warming in 9th Grade Science
}

\author{
Jill R. Gabucan (1,*), Joje Mar P. Sanchez ${ }^{2}$ \\ ${ }^{1}$ Babag Integrated School, Division of Cebu City, Philippines \\ ${ }^{2}$ College of Teacher Education, Cebu Normal University, Philippines
}

\begin{abstract}
Received: June 08, $2020 \quad$ Global warming is the primary environmental issue of the times. Due to

Revised: September 15, 2020 this, many people called for solutions and education is considered to be of

Accepted: November 10, 2020 prime importance. Reading literature has shown that students have limited knowledge and many misconceptions about global warming, hence, innovative and creative ways of teaching should be implemented in the classrooms. The study explored the effectiveness of an innovative and creative pedagogy called Strategic Intervention Material (SIM)-based Instruction in teaching global warming concepts to improve the performance of 9th-grade students in a mountain school in Cebu City, Philippines. A quasi-experimental with pretest-posttest design was conducted, with the control group exposed to modular approach and the experimental group exposed to SIM-based instruction. Data was obtained from the pretest/posttest and perception inventory were analyzed by using $t$-tests, weighted means and Pearson $r$ correlation. Study findings revealed that both groups had Below Average performances in the pretest, and the former group had Average performance while the latter group had Above Average performance in the posttest. Moreover, both groups manifested significant mean improvement from the pretest to the posttest, signifying essential use of modules and SIM in the teaching-learning process. The experimental group acquired higher mean gain than the control group and had a Very High perception towards the use of SIM in the teaching of Global Warming in science. The study concluded that SIM-based teaching is a more effective approach in improving students' performance in the concepts of global warming. Furthermore, the researchers recommend the use of SIM for remediation and regular classes, and encourage administrators, Science supervisors and teachers to SIMs not only on least mastered skills but also on all skills covered by the lesson.
\end{abstract}

Keywords: Strategic intervention material, SIM-based instruction, modular approach, global warming

(*) Corresponding Author: $\quad$ jill.rizada002@deped.gov.ph

How to Cite: Gabucan, J.R. \& Sanchez, J.M.P. (2021). Strategic intervention material (SIM)-based instruction in teaching global warming in $9^{\text {th }}$ grade science. Formatif: Jurnal Ilmiah Pendidikan MIPA, 11 (1): 15-24. http://dx.doi.org/10.30998/formatif.v11i1.6448

\section{INTRODUCTION}

Science education has been programmed by educational systems around the world, not only to inculcate scientific literacy, but also to develop environmental literacy among the students. When students become environmentally literate, they can make sound judgments on issues that may impact the environment in general. This is needed since the environment has been greatly affected by anthropogenic activities brought about by science and technology. The effects of such activities can be observed in deforested areas, eroded land sites, polluted waters and air, and even species extinction. One effect 
has been considered to be the primary environmental issue of the times - Global Warming (Bozdoğan, 2011).

Global warming is a phenomenon that occurs when there is an increase in the average temperature of Earth's land and oceans, caused primarily by the exacerbation of increasing greenhouse gases in the atmosphere (Rosidin and Suyatna, 2017; Kilinc, et. al., 2008). In the present, global warming has since become more evident as amounts of the carbon dioxide and methane have increased at an alarming rate in the last two centuries (Shahzad, 2015). Consequences of global warming include food shortage and climate change events such as unprecedented heat waves and more intense cyclones. Due to these effects, people are calling for solutions, where education is important in this context (Bangay and Blum, 2010; Skamp, Boyes and Stanisstreet, 2009).

Global warming concepts have been crucial in climate change education programs such that of the United Nations Children's Fund (2009) and The One UN Climate Change Learning Partnership (2013). Initiatives were also done to re-orient education towards alternative, transformative, and sustainable development education in order to empower people of all ages in order to participate in relevant and appropriate actions (Bangay and Blum, 2010). However, a number of studies have shown low knowledge about global warming despite the implementation of appropriate environmental education across countries. In fact, Bozdoğan (2011) revealed in a literature review that students had limited knowledge and conceptual misconceptions concerns the issue on global warming. Boyes and Stanisstreet (2001) found out that high school students had some knowledge about the global issue but also got many incorrect information. Rosidin and Suyatna (2017) found out that junior and senior high school students obtained a mean score of 3.6 out of 10, indicating that they have low knowledge in global warming.

In the Philippines, global warming concepts are embedded in the curriculum because the curriculum aims to develop well-informed citizens who can make sound decisions and judgments on environmental issues. However, Filipino students obtained below average performances in Science where global warming concepts are included. Cebu City, the locale where the participating mountain school is located, had an increasing mean percentage scores yet below average performances in the national achievement tests. The mountain schools, on the other hand, had decreasing scores in the same testing years (Figure 1).

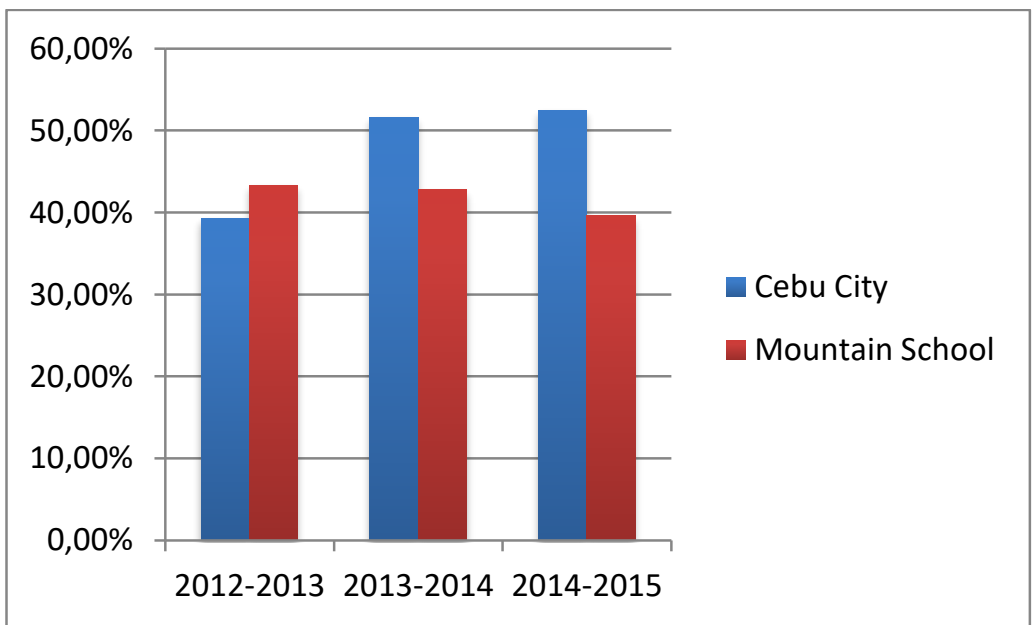

Figure 1. National achievement test results for Cebu City and the participating mountain school 
With the various studies that revealed students' limited knowledge and misconceptions about global warming, and the below average performances of students in Cebu City and the mountain school, new or innovative ways of teaching are called for. Bozdoğan (2011) called for pedagogies where students are active participants and that embed visual materials and constructivism. One of the innovative teaching strategy that also incorporates Bozdoğan's (2011) recommendation is the use of Strategic Intervention Material (SIM) as a basis of an instructional way of teaching global warming concepts. This intervention material can be integrated in an innovative pedagogical approach called SIM-based teaching.

In SIM-based teaching, an instructional material is used to re-teach concepts and skills. These materials are given to learners to help them master a competency-based skill that they were not able to develop during regular classroom teaching (Dacumos, 2016; Salviejo, Aranes and Espinosa, 2014; Bunagan, 2012). SIMs are introduced to stimulate the activity of the students, thereby increasing their level of understanding (Alboruto, 2017; Dy, 2012), enhancing students' performance in Science (Sinco, 2020; Villonez, 2018; Marimla and Dimalanta, 2015; Salviejo, Aranes and Espinosa, 2014), and affecting positively their attitudes towards science (De Roxas, 2019). Due to this, SIMs were studied in Physics (Marimla and Dimalanta, 2015; Plenos, 2015; Dy, 2015), Chemistry (Bete, 2020; Contreras, 2018; Salviejo, Aranes and Espinosa, 2014; Gultinao, 2012), and Biology (Sinco, 2020; Dapitan and Caballes, 2019) and yielded positive results; however, SIMs are rarely studied in fields of Earth Science education (e.g. Villonez, 2018).

Since the core learning area standard of Science is to demonstrate understanding of science concepts, skills, attitudes and values that would lead to students' manifestation of respect for life and the environment, bearing in mind that Earth is our only home (DepEd, 2013), SIM-based teaching was applied to the concepts of global warming. With the scenario that has shown the calls for SIM-based teaching, the study aimed to determine the approach's effectiveness in Science. Specifically, the student (a) determined the pretest and posttest performance of students exposed to modular approach and SIM-based instruction; (b) compared their scores for significant difference; (c) determined the level of their perception on the use of SIM; and (d) correlated their perceptions to their posttest scores. The results of the study would benefit especially the students in enhancing their performance and the teachers in improving the way they teach $21^{\text {st }}$ century learners; thus, the conduct of the study.

\section{METHODS}

The study utilized a quasi-experimental method of research in which pretestposttest unrandomized group design was employed. This quasi-experimental research was conducted in one of the public high schools located in one of the mountain barangays within Cebu City Division. Thiry 9th-grade students of the said school participated in the study: 15 students constituted the control group and the other half constituted the experimental group. Most of the students in both groups are females and aged 15 years old (Figure 2), and are comparable, normal and homogeneous. The control group was exposed to the modular approach while the experimental group was exposed to SIMbased instruction. 


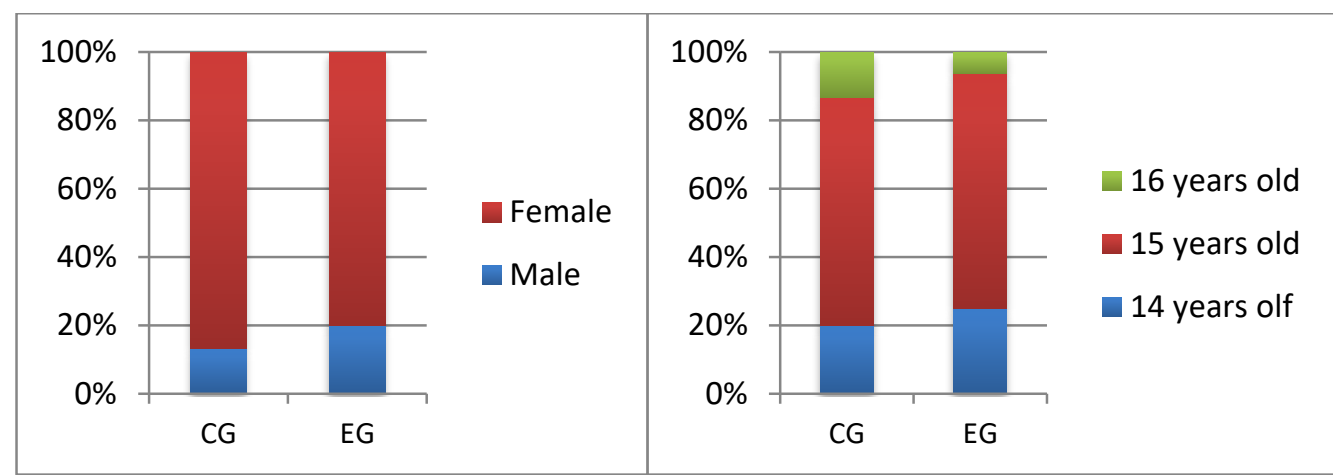

Figure 2. Sex and ages of the participants in control (CG), experimental (EG) groups

Furthermore, two instruments were used in the study. One was the validated researcher-made pretest/posttest tool consisting of 20 items, covering topics on global warming. This tool was subjected to pilot testing and a Cronbach alpha of 0.840 was obtained, indicating that the test has a good and acceptable reliability. The other tool was the perception inventory adapted from the standardized tool of Salviejo, Aranes and Espinosa (2014) that was modified into 11-item Likert scale instrument. Sample questions in the pretest/posttest are given in Figure 3.

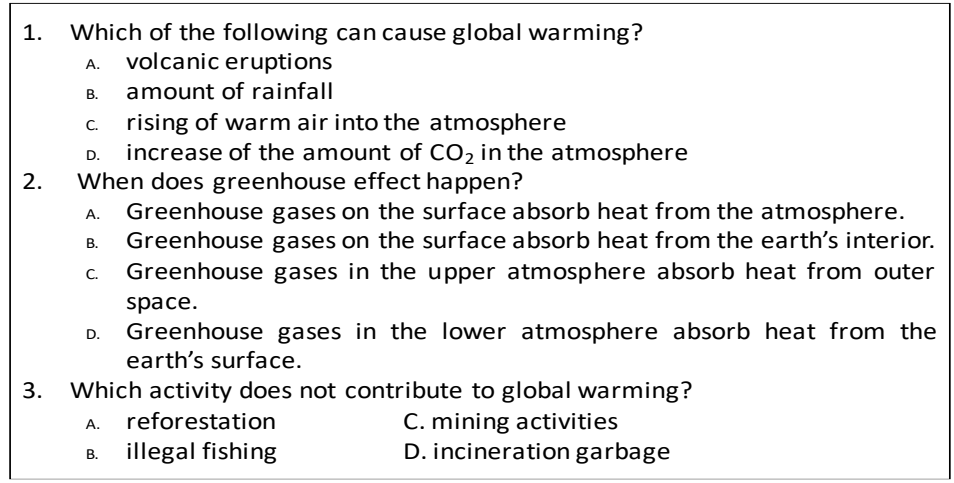

Figure 3. Sample questions in the pretest/posttest

This research commenced by asking permission from the Schools Division Superintended of Cebu City and the School Principal of the mountain school to conduct the study there. Once permitted, the researchers then asked informed consent from the parents as well as assent form from the students if they agree to participate in the study. This ethics process ensures their privacy and anonymity, and the confidentiality of their information. Afterwards, the modules were readied and the SIM was constructed. The modules are provided by the education department as the basic learning resources for Science, consisting of overview, pretest, activities, performance task, posttest and summary. The SIM consists of six general parts, namely Guide card that presents the overview and focus skills of the lesson; Activity card where the students practice a competence-oriented task; Assessment card which helps the learner in mastering the skill upon completion; Enrichment card that extends learning with additional exercises; Key card where answers of the activities are embedded, and Reference card which provides additional content of resources for further readings. The SIM was validated by five trainers of SIM-making, who are the Division Science coordinator, Division Learning Resource Management coordinator, District Science coordinator, Science teacher, and English teacher from the mountain school. The title and learning competencies of the SIM used in the study are shown below in Figure 4. 


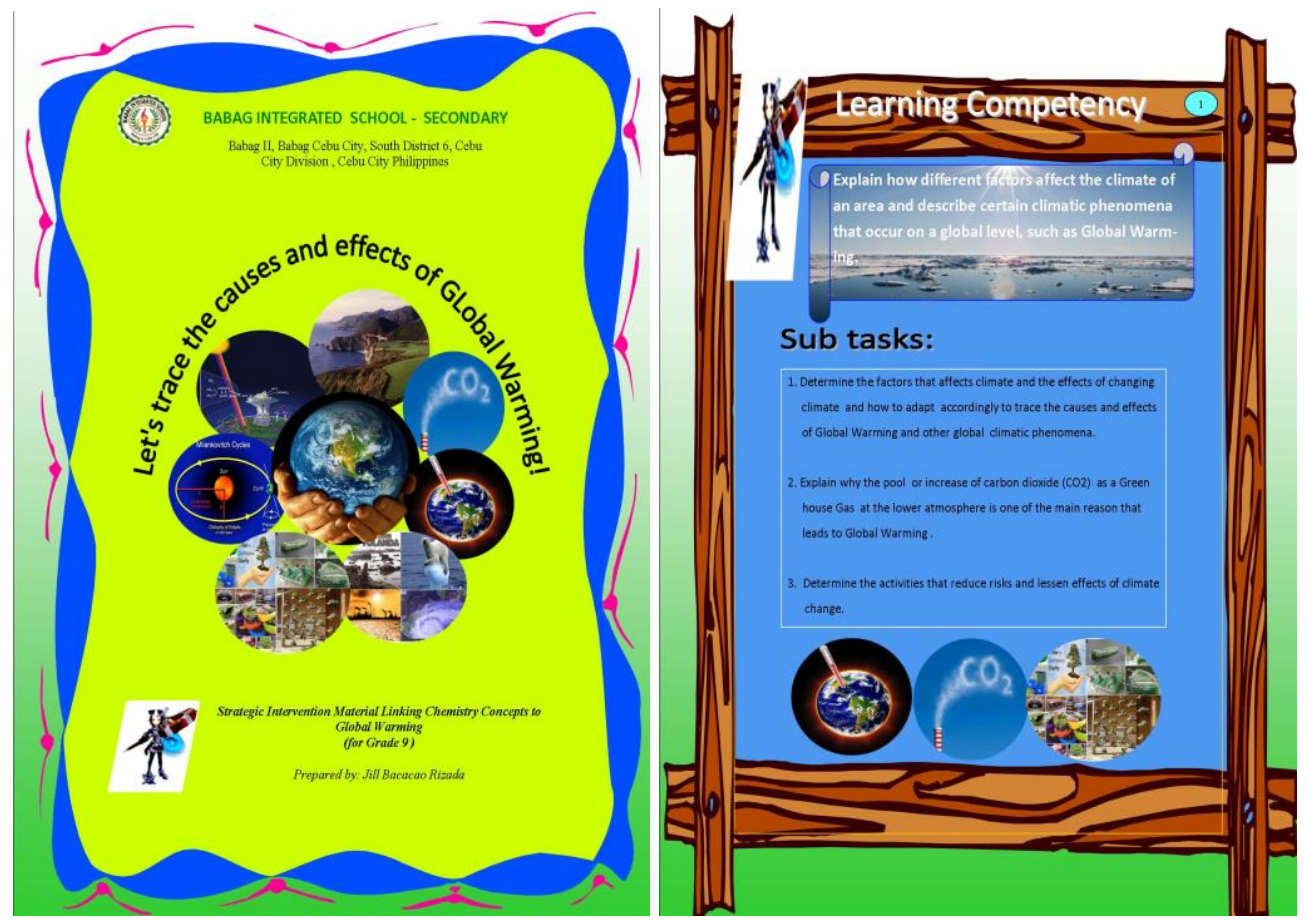

Figure 4. Title and learning competencies as reflected in the SIM

Then, the pretest was administered to the students, and pedagogical application was employed: the control group was exposed to modular approach while the experimental group was exposed to SIM-based instruction. Lastly, the posttest was administered to both groups; only the experimental group was given the perception inventory tool. The scores derived from the pretest/posttest were subjected to $t$-tests (for single and small samples, for dependent samples, and for independent samples), while data from the perception inventory were subjected to descriptive statistics (frequency, percentage and weighted mean) and interpreted based on Salviejo, Aranes and Espinosa's (2014) descriptions: 1.00-1.80 (Very Low), 1.81-2.60 (Low), 2.61-3.40 (Moderately High), 3.42-4.20 (High), and 4.21-5.00 (Very High). The level of perception and posttest performance were subjected to Pearson correlational analysis. All tests were conducted at $\alpha=0.01$.

\section{RESULTS \& DISCUSSION}

\section{Results}

The results of the quasi-experimentation are illustrated in Figure 5.

Based on Figure 5, both control and experimental groups had significantly lower actual means (4.87 and 4.73, respectively) than the hypothetical mean (the passing standard, $75 \%$ of the perfect score), which means that both had Below Average performances in the pretest. Further analysis of the pretest resulted in $t=0.277$ and $p=.392$ with a mean difference of 0.14 , indicating that there was not significant difference in the pretest performances between the groups. This suggests that the groups had comparable performances before introducing the concepts on global warming. Below average performances might be attributed to the fact that the students were not formally exposed to the global warming topic. 


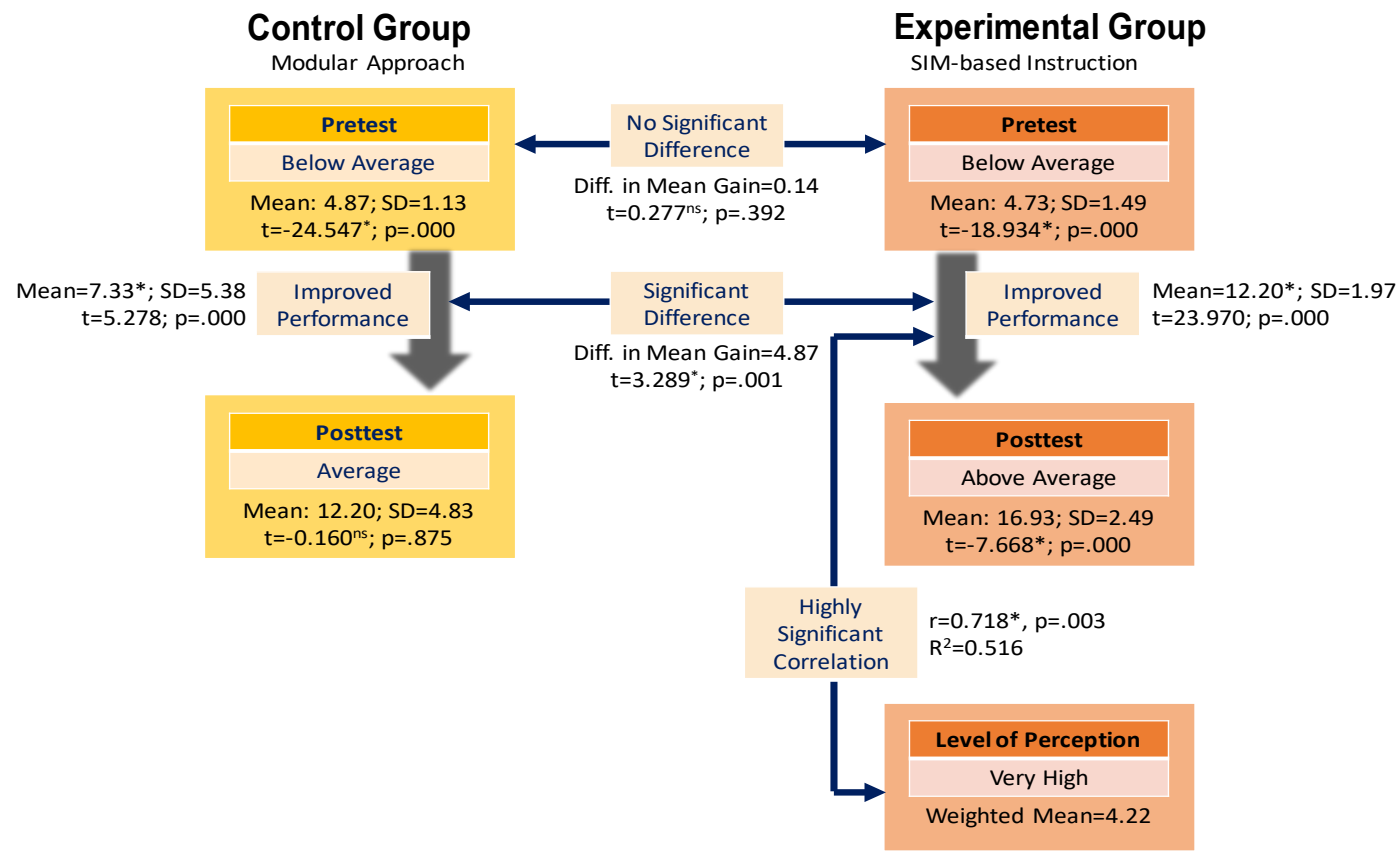

Figure 5. Graphical presentation of the study results

The control group obtained a mean of 12.20 and SD of 4.83, which analysis found out that this is not different from the hypothetical mean $(t=0.160, p=.875)$; thus, the students' performance in this group is Average. On the other hand, the experimental group got a mean of 16.93 and SD of 2.49 , which statistical testing found out that this is a highly significant difference $(\mathrm{t}=7.668, \mathrm{p}=.000)$; hence, the members of this group had Above Average performances. This means that both groups had performances on par with the Philippine standard of $75 \%$. Mean gains from the pretest to the posttest were 7.33 for the control group, and 12.20 for experimental group. Statistical testing on these mean gains resulted to $t=5.278$ and $p=.000$ for the control group and $t=23.970$ and $p=.000$ for the experimental group. These results revealed that both groups had significant mean improvement before and after the exposure of modular approach and SIM-based instruction in teaching global warming concepts.

The mean gains of the control and experimental groups were analyzed, and the results gave $t=3.289$ and $p=.001$, signifying that there was a significant difference that exists between the performances of the two groups. The experimental group had a higher mean gain that the control group. This means that the SIM-based instruction was more effective than the modular approach. The creation of the SIM with personalized design and simplified activities contributed to its effectiveness.

Results of the perception inventory revealed that the 9th grade students had a mean perception of 4.22. This means that the students have very high perception towards the use of SIM in the teaching of global warming in Science. Correlational analysis between the students' mean gain and perception level resulted to these values, $r=0.718$, $\mathrm{p}=.003$ and $\mathrm{R}^{2}=0.516$. This means that there was a highly significant correlation that exists between the two variables. Higher perception may lead to higher improvements when SIMs are used in teaching science concepts. 


\section{Discussion}

The modules and SIMs are effective in improving the students' knowledge before and after implementing the learning materials to them. This significant improvement adheres with the principles and standards as stipulated in Republic Act 10533 or the "Enhanced Basic Education Act of 2013". The use of modules and SIM is in coherence with the principle of having a learner-centered curriculum, as the students are involved in the teaching-learning process. Such use was also in adherence to constructive, inquirybased, reflective, collaborative and integrative pedagogies. Both approaches are constructivist in nature because students are actively engaged in the learning activities provided by the modules and SIM. Also, the approaches are inquiry-based as questions are raised during the engagement of students in the activities. Moreover, such approaches are reflective as the use of the learning materials were towards self-directed learning, on which students become accountable of their own learning. These materials included collaborative activities and provided integrative characteristics by extending knowledge and skills to other fields of study. Thus, the significant improvement provides evidence that the modules and SIM are learning resources coherent with the $\mathrm{K}$ to 12 program of the country.

The modules have a structure; these materials contain elements of instructions, specific objectives, teaching-learning activities and evaluation. The significant mean improvement of the use of modules supports the studies of Alelaimat and Ghoneem (2012) and Ali, et. al. (2010), which states that modular teaching is more effective than traditional approaches of teaching. The use of modules relates the interest among the students as they learn at their own pace and become aware of the science involvement in their everyday life (Olteanu, Dumitrescu, Gorghiu \& Gorghiu, 2014). Moreover, this finding concur with the theory of Gagne (1985) as the use of modules requires the learning tasks to be organized in different levels in order to gain improvement in the students' performance.

The use of SIM-based teaching speared to be more effective as it yielded the highest level of performance compared to the use of modules. This shows the efficacious nature of SIM. The effective characteristic of SIM could be due to the way this intervention material is made. SIM incorporates many sound pedagogical approaches such as peer tutoring and brainstorming, and several science process skills such as observing, inferring, hypothesizing, interpreting and problem solving. Also, SIM guides the students towards the attainment of the competencies by putting dialogue boxes, having simplified activities, and emphasizing understandable concept and task presentation. The use of colorful and interactive visuals such as pictures, graphs and illustrations support enjoyable learning experience while catering to the needs and interests of the students. So, the process of the intervention contributes largely to the effectiveness of the SIM characteristics.

Students are involved in simplified yet meaningful learning activities that lead to the significant improvement from the pretest to the posttest. The significant improvement derived from the SIM-based teaching supports the studies of Sinco (2020), Villonez (2018), Marimla and Dimalanta (2015), Dy (2015), Plenos (2015), Barredo (2014), Salviejo, Aranes and Espinosa (2014), and Gultiano (2012), which all stated that the use of SIM improves the performance of students in science subjects. Dacumos (2016), Plenos (2015), Barredo (2014) and Gultiano (2012) state that the SIM is effective in mastering the competency-based skills in science while manifesting a positive transfer of learning. Likewise, the results conform to the theory of Boyatzis and Varghese (1994) who state that the use of colors in presenting lessons could enhance productivity and performance of students. The combination of colors used in SIM makes the students 
psychologically respond to the process like attracting their attention, sustaining interest on the subject, and giving excitement on what would happen next in the lesson. Moreover, Dy (2014) states that today's learning environments should be indulged with new, innovative and creative ways in order to maximize facility of the presentation of science concepts with each and accuracy.

The students expose to SIM have a very high perception towards the use of SIM in teaching global warming concepts in science. This could be due to the fact that learning activities included in the intervention material let the students explore several science process skills. These process skills were presented in the intervention material in a simplified, interactive, colorful and meaningful way to them. The use of the material allowed them to practice new skills obtained through simulations, problem-based learning, and contextualization. The interests of the students towards the attainment of the process skills embedded in the SIM lead them to have high perception in the use of the materials. The very high perception towards the use of SIM in science is affirmed in the results of the students' perception inventory, which portrayed Strongly Agreed (SA) and Agreed (A) items. The students strongly agree with the use of SIM in teaching science due to the material's user-friendly, personalized, customized, enjoyable, worthanswering, relevant and understandable in nature. This finding supports the use of SIM, which significantly increases their performance in Science. The studies of De Roxas (2019) and Barredo (2014) showed that students manifested positive transfer of learning when the material is given to the students. Salviejo, Aranes and Espinosa (2014) find out the use of SIM gained positive perception among the students wherein they find it enjoyable, interesting and contributing positive attitude towards the subject.

Ultimately, the study provides an innovative and creative means of teaching global warming. The use of SIM, which has colorful and interactive visuals, can support enjoyable learning experience about the environmental issue. This is coherent with the results of Oluk and Özalph (2007) when they find out that colorful visuals such as cartoons and animations made students' learning easier because these visuals catch the attention of the students and make them more interesting with the global warming and other environmental issues. The present finding also has similar results with Taber and Taylor (2009) when introducing visual educational resources that develop conceptual understanding of the environmental issue. Lastly, this study concures with the study of Bozdoğan (2011) who finds out that experimental studies obtained positive results because students become active participants in the study while they are introduced to visual learning materials, leading to more enhanced knowledge level about global warming.

\section{CONCLUSION}

Learning concepts and skills in Science should be innovatively and creatively delivered to the students. Embedding such creative ways in the instruction gets the attention of the students and boosts their interest in learning both easy and difficult concepts and skills. Based on the findings of the study, the Strategic Intervention Material (SIM)-Based Teaching is a more effective approach in improving students' performance in the concepts of Global Warming in Science. Boyatzis and Varghese's theory, which states that color evokes emotion and psychological responses which could enhance student productivity in learning, and Dy's theory, which states that learning environment should be deluged with new and innovative materials in order to have effective learning, were affirmed in this study. 


\section{ACKNOWLEDGEMENT}

The authors extend their gratitude to their mentors from the University of the Philippines Cebu, as well as to their tool and SIM validators from the Department of Education, Cebu City Division and Babag Integrated School. They also give their thanks to Dr. Elisa Lapa for the statistics guidance and to the students who voluntarily participated in this study.

\section{REFERENCES}

Alboruto, V.M. (2017). Beating the numbers through strategic intervention materials (SIMs): Innovative science teaching for large classes. AIP Conference Proceedings, 1848, 060014. https://doi.org/10.1063/1.4983982

Alelaimat, A.R. \& Ghoneem, K.A.A. (2012). The effect of educational modules strategy on the direct and postponed study's achievement of seventh primary grade students in Science, in comparison with the conventional approach. Higher Education Studies, 2(2), 40-60. https://doi.org/10.5539/hes.v2n2p40

Ali, R., Ghazi, S., Khan, M., Hussain, S. \& Faitma, Z. (2010). Effectiveness of Modular Teaching in Biology at Secondary Level. Asian Social Science, 6(9), 49-54

Bangay, C. \& Blum, N. (2010). Education responses to climate change and quality: Two parts of the same agenda? International Journal of Educational Development, $30(4), 335-450$

Barredo, K. J. (2014). Evaluating the Effectiveness of Using Strategic Intervention Material in Improving the Academic Performance in Science. SlideShare. http://www.slideshare.net/kbarredo/action-research-for-strategic-interventionmaterials

Bete, A.O. (2020). Students' knowledge and process skills in learning grade- 8 chemistry. Journal of Research, Policy \& Practice of Teachers \& Teacher Education, 10(1), $1-13$

Boyatzis, C.J. \& Varghese, R. (1994). Children's emotional associations with colors. The Journal of Genetic Psychology: Research and Theory on Human Development, 155(1), 77-85. https://doi.org/10.1080/00221325.1994.9914760

Boyes, E. \& Stanisstreet, M. (2001). School students' ideas about the "Greenhouse Effect" a decade on. Canadian Journal of Environmental Education, 6, 77-101

Bozdoğan, A.E. (2011). A collection of studies conducted in education about "global warming" problem. Educational Sciences: Theory \& Practice, 11(3), 1618-1624

Bunagan, F. (2012). Science intervention material. Retrieved from http://www.slideshare.net/felixbunagan/strategic-intervention-aterial

Contreras, S.J. (2018). Utilization of manipulative and interactive strategic intervention material (MI-SIM) in Chemistry 9. ASTR Research Journal, 2, 45-65

Dacumos, L.P.N. (2016). Perspective of secondary teachers in the utilization of science strategic intervention material (SIM) in increasing learning proficiency of students in science education. AsTEN Journal of Teacher Education, 1(2), 1-15

Dapitan, D.A. \& Caballes, D.G. (2019). Exploratory effects of strategic intervention materials in General Biology 2. Biometrics and Bioinformatics, 11(3),

De Roxas, K.A.D. (2019). Strategic intervention materials for enhancing physical science instruction in Grade 12 at San Nicolas National High School. International Journal of Research in Engineering, Science and Management, 2(6), 607-608 
Department of Education. $\mathrm{K}$ to 12 curriculum guide: SCIENCE (grades 3 to 10). http://www.deped.gov.ph/sites/default/files/page/2014/Final\%20Science\%20CG \%20310\%2005.08.2014.pdf

Dy, J. (2014). Strategic Intervention Materials (sim) in Teaching Science IV (Physics): Its Effectiveness. HubPages. http://hubpages.com/education/Sample-of-a-Brief-FullVersion-of-a-Research-Study-Strategic-Intervention-Materials-SIM

Dy, J. (2012). How to Develop A S.I.M. (Strategic Intervention Materials)? HubPages. http://hubpages.com/education/HOW-TO-DEVELOP-A-SIM-STRATEGICINTERVENTION-MATERIAL

Gagne, R. (1985). The Conditions of Learning (4th Edition). New York: Holt, Rinehart \& Winston.

Gultiano, A. (2012). Effects of strategic intervention material (SIM) on the academic achievements in Chemistry of public high school students. Retrieved from http://www.slideshare.net/neoyen/strategic-intervention-material.

Marimla, A.S. \& Dimalanta, O.G. (2015). Development and evaluation of strategic intervention material in Science V. Research Journal of Social Sciences, 8(12), 16.

Olteanu, R.L., Dumitrescu, C., Gorghiu, G. \& Gorghiu, L.M. (2014). Studying sciences through the integrated science modules. European Journal of Sustainable Development, 3(3), 35-42. https://doi.org/10.14207/ejsd.2014.v3n3p35

Oluk, S. \& Özalp, I. (2007). The teaching of global environmental problems according to the constructivist approach: As a focal point of the problem and the availability of concept cartoons. Educational Sciences: Theory, \& Practice, 7(2), 881-896

Rosidin, U. \& Suyatna, A. (2017). Teachers and students knowledge about global warming: A study in smoke disaster area of Indonesia. International Journal of Environmental \& Science Education, 12(4), 777-785

Salviejo, E., Aranes, F. \& Espinosa, A. (2014). Strategic intervention material-based instruction, learning approach and students' performance in Chemistry. International Journal of Learning, Teaching and Educational Research, 2(1), 91123.

Shahzad, U. (2015). Global warming: Causes, effects and solutions. Durreesamin Journal, 1(4).

Sinco, M.G.M. (2020). Strategic intervention materials: A tool in improving students' academic performance. International Journal for Research in Applied and Natural Science, 6(5), 1-22

Skamp, K.R., Boyes, E. \& Stanisstreet, M. (2009). Global warming responses at the primary secondary interface: Students beliefs and willingness to act. Australian Journal of Environmental Education, 25, 15-30. https://doi.org/10.1017/S0814062600000379

Taber, F., \& Taylor, N. (2009). Climate of concern - A search for effective strategies for teaching children about global warming. International Journal of Environmental and Science Education, 4(2), 97-116

The One UN Climate Change Learning Partnership (2013). Resource Guide for Advanced Learning on Integrating Climate Change in Education at Primary and Secondary Level. United Nations Institute for Training and Research

United Nations Children's Fund (2009). Climate change and environmental education. Child Friendly Schools Manual. New York: UNICEF

Villonez, G.L. (2018). Use of SIM (strategic intervention materials) as strategy and the academic achievement of Grade 7 students on selected topic in Earth Science. PUPIL: International Journal of Teaching, Education and Learning, 2(3), 78-88 